\title{
Robust Edutainment For On-line Course Delivery
}

David L. Sturges, (E-mail: dsturges@panam.edu), University of Texas-Pan American

\begin{abstract}
Every college and university in the United States faces the same dilemma: increasing enrollment needs that outstrip budgets' abilities to add physical plant. On-line education is perceived to be a potential contributor to meeting the need for accelerating growth of enrollments while requiring less budget commitment than required by building new physical plant. The concern is developing a method of on-line course delivery that ensures the level of quality of course content to parallel the perceived quality of traditionally delivered courses. To be attractive to students as a learning option and then to be capable of maintaining the learner's interest to motivate completion of the course and, subsequently, degree programs, course materials must incorporate the tools to create edutainment. Simply, edutainment is course delivery in a style and format with diverse components that interest and educate in a way that keeps the learning returning for more. During the past few months, technology has introduced capabilities of producing edutainment, robust course content, at costs that make it very feasible as a course delivery option in any degree program.
\end{abstract}

\section{Introduction}

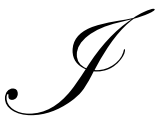

n 2001, the Texas Higher Education Coordinating Board adopted long-term goals to increase student populations of Texas colleges and universities by 500,000 by 2030 . The response of the University of Texas System and the system components was to incorporate these goals into their own strategic plans. In the case of the (School Name) (School Initials), the results were three overarching goals: (1) to improve student access and success, (2) to be a state leader in the preparation and production of public school teachers, and (3) to become the doctoral research institution in (Area of State). (Closing the Gap, THECB Report, 2001)

Access for students and retention of students was first among these overarching goals. The implementation of programs to meet these overarching goals potentially requires doubling the size of the (university) physical plant. This solution is cost prohibitive. Alternative methods must be created to deliver course content ensuring that access to the population is available and that contents and implementation are such that students are more likely to complete courses and, eventually, degree requirements. One of the options is on-line courses delivered over the Internet: "Distance Learning." (University Strategic Plan, 2002).

In 1998, the University of Texas System established the UT Telecampus as the $15^{\text {th }}$ institution in the UT System. The intent was for the Telecampus to provide the support necessary for faculty and students to successfully implement a "distance learning" option for students. Two assumptions were the basis for initializing the new campus approach. First was that faculty had, could acquire, or could be provided with the technical expertise to create effective on line courses. Second was the assumption that students had sufficient computer literacy skills to access and successfully navigate the various categories of on-line courses coming on-line during 1998 to the present.

Somewhere along the way a roadblock developed on the superhighway of Internet-based education: neither faculty nor students flocked to this new delivery method from traditional colleges and universities. In effect, the diffusion of this innovation has marched on a different path and timetable from most "Information Technology" experts' predictions. 


\section{Distance Education}

One realization that occurs to many trying to understand what is happening in the current state of adoption of technologies in the delivery of educational courses is a confusing application of terms exists. A general label, "Distance Education," is applied to the use of technology to supplement or enhance educational opportunities. But, the activities and concepts encountered in the world of "distance learning" are diverse and, in some instances, contradict the connotation of the label.

The label "distance learning" traces its genealogy to the adoption in the 1970s and 1980s of television or audio linkages to offer classroom connections between a central production point and one or more off-site technology centers equipped with appropriate electronic production capabilities. Once distance centers were installed and dedicated connections established, additional students for any one course could be added for little marginal increase in cost.

College and university extension programs were quick to capture the technology as its development corresponded with the increase in public television outlets, which tended in many instances to be associated with colleges and universities. This marriage made delivery of courses to students in separated geographic locations at once easy and, secondly, attractive to potential students. Until this time, extension programs were limited to printed course lessons distributed by mail or other physical delivery methods. The concept of viewing a lecturer and seeing demonstrations and applications of concepts made television courses a major step forward in improving the quality of extension offerings.

However, schools using this technology found that attracting students who could not be on campus, the driving motivation behind "distance learning," was not the operative motivation in practice. Residential students used these offerings as a method to accelerate degree completion. Students who were not given permission by administrators to take heavy loads could take fifteen to eighteen hours in a semester in residence and could supplement the workload with one or two courses via extension. These courses could be transferred to the residential record to apply against degree credit at any time.

The phenomenon of students using "distance learning" course offerings to supplement regular class offerings led to the introduction of the terms "flexible learning" or "flexible scheduling." This concept recognizes that a prime target for delivery of these courses is the traditional student who seeks additional opportunities. Their desire may be to accelerate degree completion or to provide scheduling flexibility when course times do not meet student needs.

In general, comments by students enrolled in Flexible Schedule courses suggest that the population falls into two categories (Student Evaluations, 2001-02). The first category is students who have the skills and capacity to be successful in on-line courses that are dominated by written study materials. The course content focuses on textbooks, written notes presented on an Internet site, on-line quizzes, and other written support materials. Students who have the ability to read and comprehend effectively are successful in this approach.

The second group is students who find the on-line experience to be troublesome. These students are those who developed their educational techniques from years of courses built on personal association with faculty members. These students tend to be "visual learners" who require visual components to course content as well as lecture and written components. Many faculty incorporate visual components into class content using video tapes to show illustrations or to include content from sources not readily available.

In some educational discussions, the difference between these two groups is sometimes explained as the "left brain/right brain" process of brain function (Sperry, 1972). It appears that for Internet on-line education to reach a level of effectiveness and efficiency to encompass all students, then an effort must be made to focus course content extension to make the on-line option effective for all student types. 
This suggests that courses designed to optimize the learning capabilities must be constructed with robustness necessary to activate learning styles to incorporate the full learning capacity of students. This has been referred to as the shift from Broadcast learning to Interactive Learning (Tapscott, 1998).

Figure 1

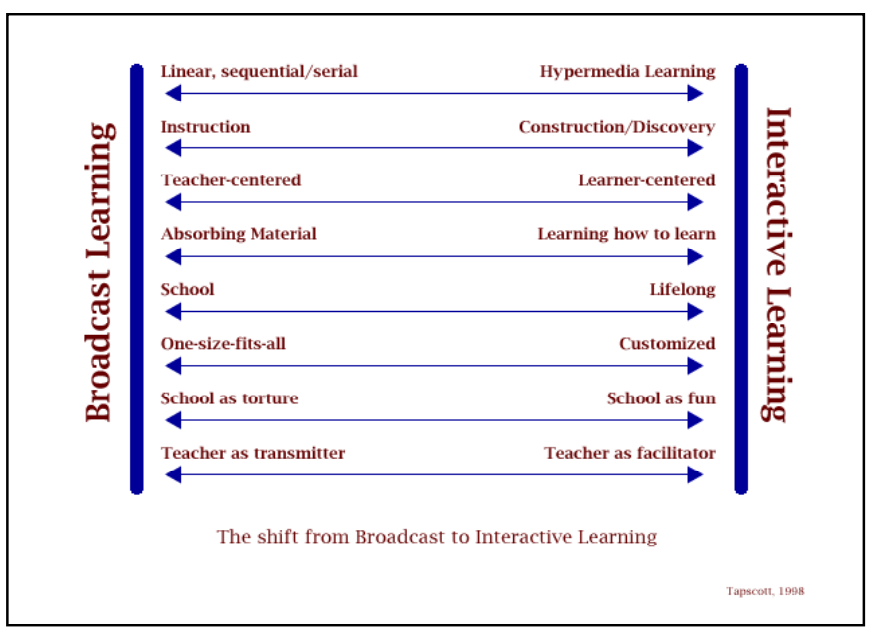

Figure 2

Quick Time ${ }^{\mathrm{TM}}$ and a Graphics decomposer are needed to see this picture

"Broadcast Learning" is the name applied to the concepts and techniques that are typically associated with traditional classroom learning. "Interactive Learning" is the concepts that have been introduced as learning requirements addressing the learning needs of those reared in computer/digital environments of the nineties and early 2000s. The courses currently offered in Distance Learning or Flextime Scheduling and can be evaluated using these criteria.

\section{Internet Course Development}

A review of the types of web-based course materials and techniques for the Interactive Learning components suggests a hierarchy of course types based on criteria such as the degree of technical expertise required to produce the web-based materials and the degree of computer literacy required to function in a webbased Interactive Learning environment. In general these criteria produce five categories of web-based course material (Sturges and Minor, 2001). The five categories are illustrated in Figure 2.

Successful implementation of on-line learning depends on systemic recognition of the levels of production and use and their differences. More importantly, on-line learning will not achieve the projected level of service envisioned by administrators until recognition is made in academic policy considerations. As the techniques of production evolve from OL-1 to OL-5, the time, effort, equipment, personnel resources, and faculty expertise needs go up as well. The result is that producing an OL-5 course offering is a major commitment in terms of fact-finding, content writing, and creative presentation. Until these efforts are rewarded in academic merit, tenure, and promotion consideration, faculty have no motivation to develop the skills necessary to successfully operationalize the on-line educational environment (Sturges and Minor 2001).

In order to produce a resource to meet the needs of increasing student access exponentially to the availability of faculty, then OL-5 courses are the target. It is only at this level of production that the ability to enroll more and more students for limited faculty resources is possible as more shift is made to student-centered learning. The concern has been that developing courses at this level is designed to remove faculty from the process for delivery and, therefore, reduces the components that make traditional college experiences more successful. The goal then, in order to create a robust educational experience, is to create OL-5 courses that include considerable faculty personality in courses' content. 
Figure 3

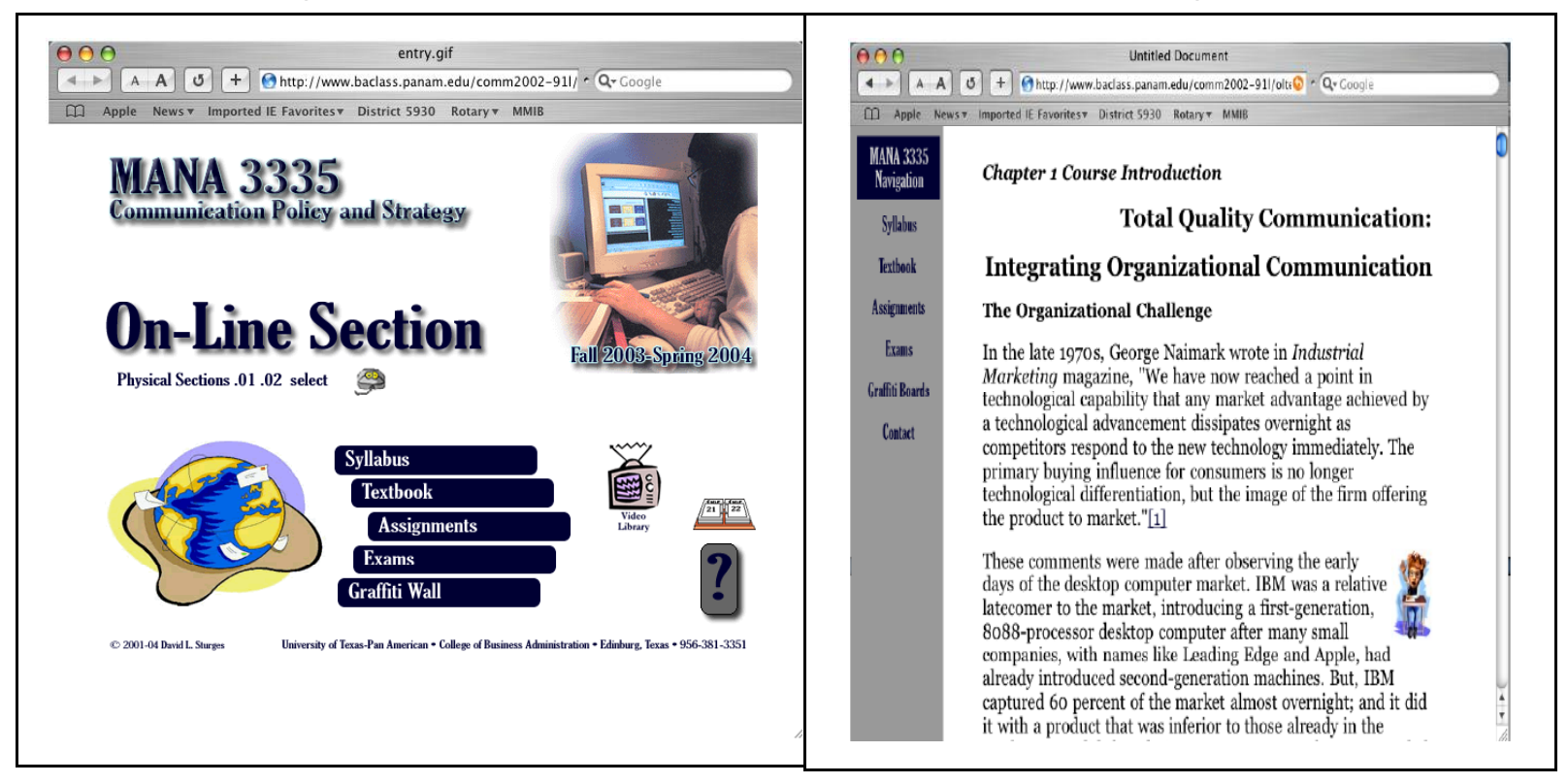

\section{Student Access And Retention}

This paper is targeted at one goal suggested by the need to meet the THECB challenge: to provide concepts to create open learner access to quality degree programs leading to a bachelor's degree. These concepts are based on the incorporation of cost effective methods to create "edutainment," courses that include robust learning with a format and style that is attractive enough to motivate student access and to promote student's interests until program completion.

Producers of on-line course resources have recognized the advantage of "edutainment" for several years. In fact, the term "edutainment" is borrowed from commercial applications that turn developmental educational software targeted toward pre-elementary and elementary learners into game formats for learning. A majority of educational software for topics ranging from English usage to mathematics is based on using game associations with the basic learning concepts as a way to attract and retain learner interest. The learners weaned on many of these edutainment products are now reaching ages where higher education is their arena. Already, the professorate is experiencing pressures to improve the entertainment content of traditional elective courses (Bartlett, 2003).

Many advisors to on-line course development suggest the game approach to add interest to on-line courses through interaction between the resources and the learner. The degree to which these multimedia components can be added to course materials differs from the levels of OL-2 to OL-5. As the application moves upward in the on-line category definitions, the type of gaming techniques increases in complexity.

As an example, Figure 3 shows the entry page for an on-line course. It includes considerable interaction for learners accessing the course, including responses to mouse movement by changing the graphics and description information. A learner moving the cursor to the "Syllabus" button would see a descriptive narrative pop up in the space occupied by the Globe drawing. (visit http://www.baclass.panam.edu/comm2002-911/entry.htm)

The course materials include at least three distinct gaming elements. The first element is the "pop-up" quiz to provide reinforcement of specific reading concepts, as well as examples of the type of objective question that might be encountered. Figure 4 shows a passage from the on-line text that contains a reference to a "pop-up" quiz called a "Kwickie Kwiz." The entry to the textbook identifies the graphic that opens the pop-up. In this case, it's the student sitting at a desk with his hand raised. Clicking on this graphic opens the quiz, shown in Figure 5. 
Figure 5

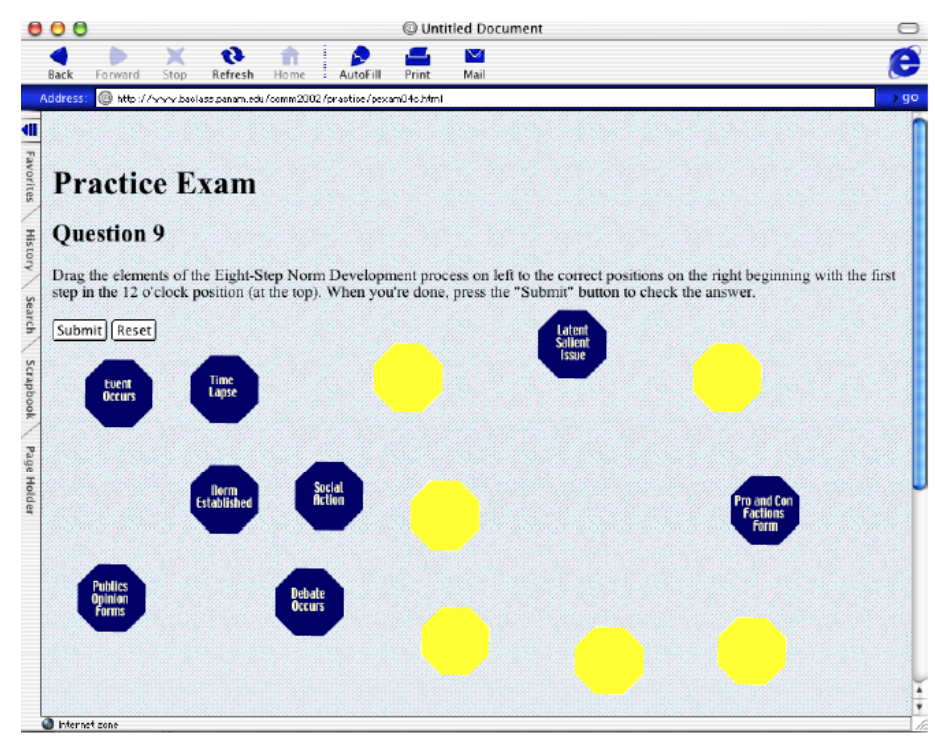

Figure 6

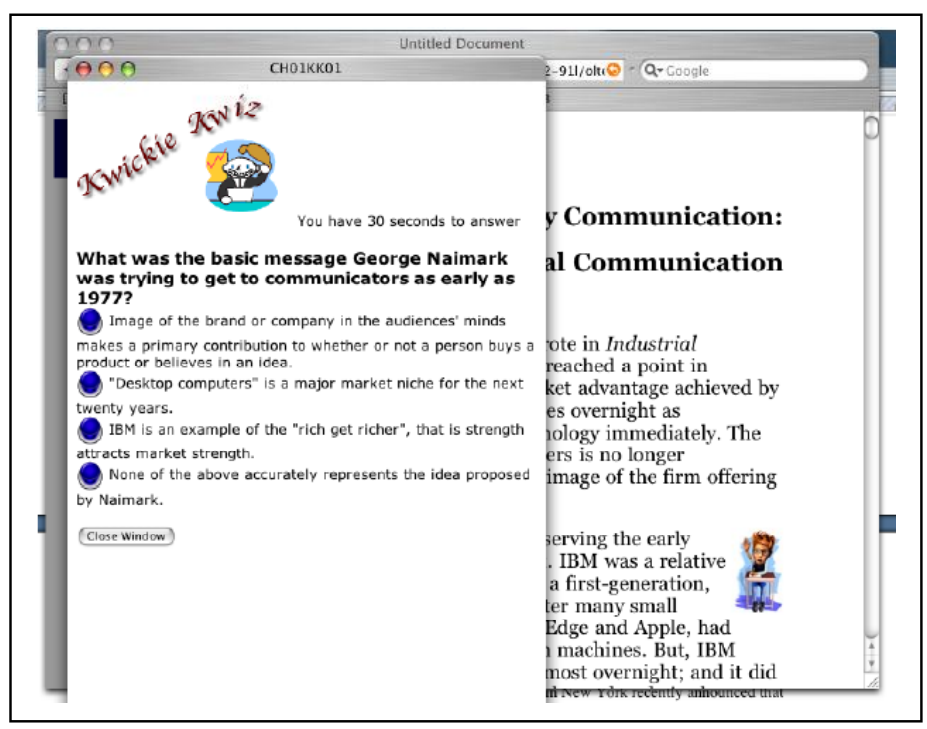

Other gaming techniques to reinforce reading concepts include the use of JavaScript to create drag-and-drop models. Figure 6 shows an example with two of the concepts on the left already dragged-anddropped on the target locations to the right. After completing the drag-and-drop process, the completed model is "submitted" where it is analyzed and a response on correctness is returned. In addition to drag-and-drop, other JavaScript gaming techniques that can be used include discovery tiles, where door-like tiles are opened to reveal information under them that can be used to match other concepts and information or to create depictions of sequential concepts. And lastly, animation and video can be placed to enhance a reading concept.

As an example, Figure 7 shows a text passage that includes a "light bulb" graphic that indicates a study enhancement called a "Study Helper." In this case, the Study Helper is a Macromedia ${ }^{\mathrm{TM}}$ Flash $^{\mathrm{TM}}$ animation to illustrate a concept introduced in the reading.

These gaming elements are enhanced by the addition of video snippets to course materials. These are short videos that are delivered in a file format that allows the video to be shown using an Internet browser as a video player or using a video player as a browser helper application. This technique required video to be downloaded, then played. Early applications of software meant that considerable time was required to download the video file before it could be viewed. Technology advanced allowing video to be set up for "progressive" download, meaning that the video front end would begin playing while the backend downloaded. The result was a brief delay in the video's start, but one that was tolerable. Figure 8 shows a page from the course text with a video reference. Clicking on the television starts a video of a one minute commercial that illustrates one of the issues discussed in the reading. 
Figure 7

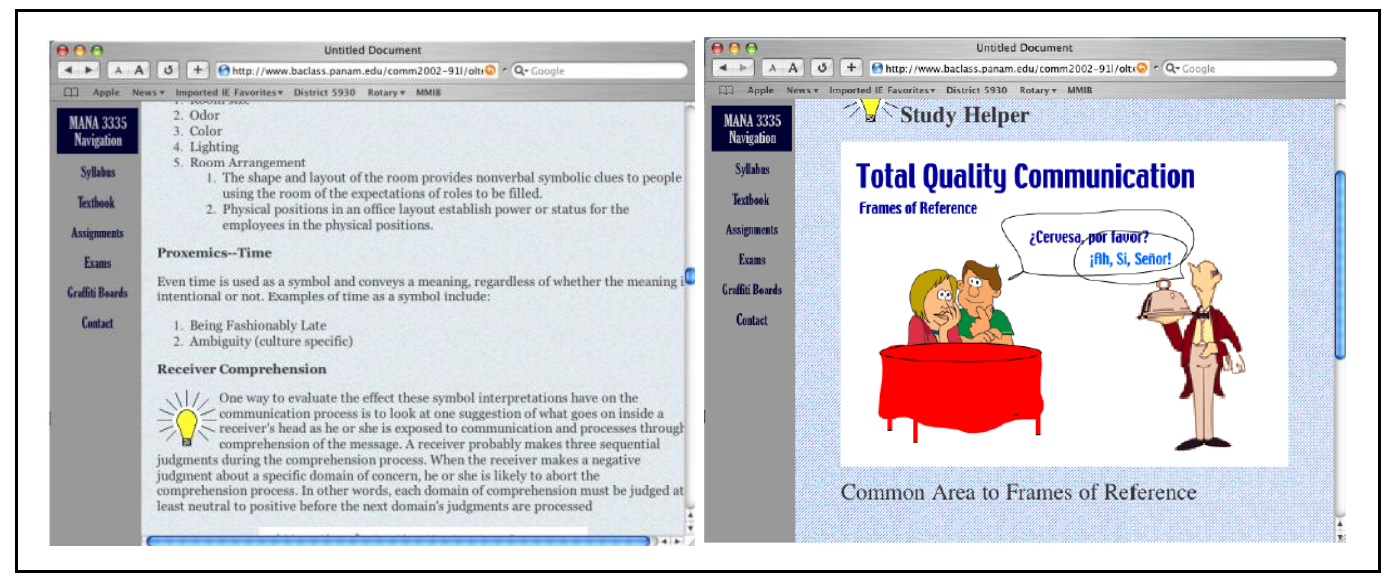

Streaming video technology permits incorporation of video into course content that previously was unavailable. This is potentially a major leap in the learning experience from what has been the delivery techniques developed during the past few years and exemplified in course currently offered nation-wide and in the (University's) Center for Distance Learning. In fact streaming video technology has become an often used component or ancillary element in many courses, on-line or physical sections. Baruch University in New York recently announced that business school lectures were to be placed on streaming video 36-48 hours after the lecture to permit students to access the lectures if they missed the lecture, or need re-exposure to some of the concepts or ideas covered in the lecture (Olsen, 2003).

They join a list of many universities adding the technology to stream video to learners. In most of these applications, the technique is to create a video that mimics the use of video tape or, in earlier days, 16-millimeter movies. These are usually thirty minutes to an hour in length and discuss or dramatize a topic in depth. Students exposed to videos of this length generally comment about the perception of the "boring movie" or "a "waste of time" as they apparently have difficulty in focusing on the point or points made in the video and their relationship to study concepts.

Figure 8

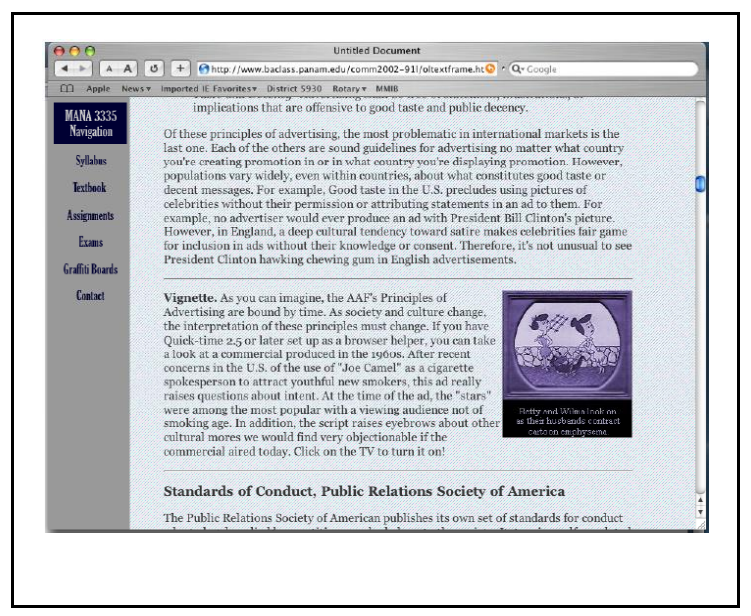

During the past few months, technology has introduced tools that provide more cost effective options to meet the needs to create robust, personalized, educational experiences that will make the on-line educational experience with OL-5 courses more effective and efficient. For any on-line course offering to achieve a level of robustness to make it an attractive and effective learning experience for the broadest count of the population, it must be designed at a level of OL-5, but with a significant visual component to extend the course's "edutainment." The course's content must be attractive to the participant as well as including significant uses of visual support to provide both personal feelings regarding the course content as well as deeper comprehension of course material. But the video addition cannot be long lectures. Such use is counterproductive to the reason for adding video as an attraction and retention tool. Therefore, the video enhancements need to be short, precise, concise and entertaining videos. More importantly, their relationship to the course content must be clearly defined by their reference in the context of course materials. As an example, Figure 9 shows a segment of the course syllabus with an embedded video. Clicking on the "Movie Poster" in the syllabus opens a streaming video player to show the video in real time, it starts in about 
two to three seconds and plays until stopped or the streaming video is completed. In addition to providing visual expression of course information, the video also provides a visual of the instructor himself for students to achieve a type of face-to-face contact to establish more personal feelings in the transmission of course information.

Figure 9

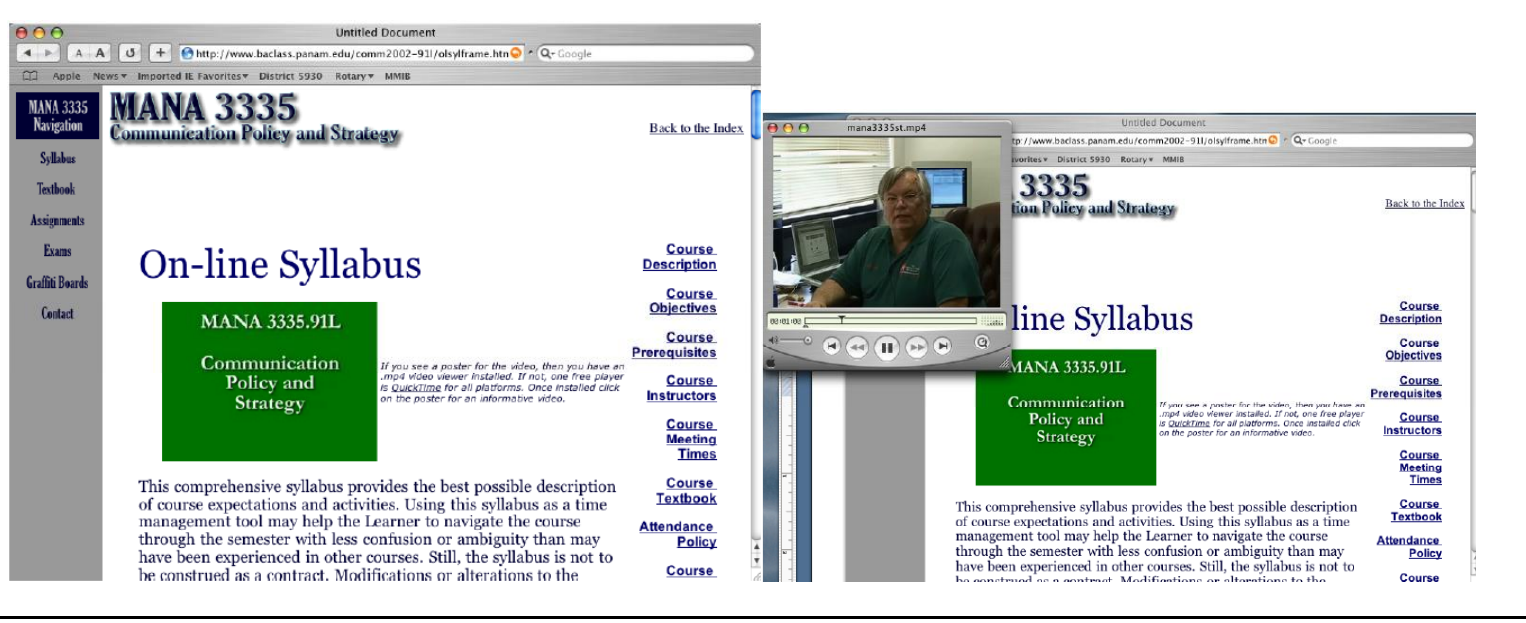

Post-production, non-linear editing, streaming video production software and streaming server software are now available at costs that allow any department or academic unit to incorporate this technique in a very cost effective manner. Our College of Business Administration and (University) already possess the technology to implement such a program. In addition to the WebCT capability of the Center For Distance Learning, streaming servers are already in place. The Department of Management, Marketing and International Business has already set up production and delivery of the elements required for the robust edutainment. The in-department capability adds a major component of advantage over previous methods for producing such videos by depending on production capabilities of university Information Technology or Television Production departments. Learner progress can be assessed in the discussion boards or chat rooms. Concepts identified as particularly problematic for learners can have a response video prepared, edited with titles, enhanced with graphic support, expanded with other video production techniques, converted to streaming video, and made available to learners in the course to access in about thirty minutes.

As an example, class learners in the recent semester were expressing concerns about how to prepare for exams in the discussion board. A three-minute video was prepared of the instructor explaining how to approach exam preparation. It had introduction and illustration graphics added. It was digitized and converted to a streaming video format and placed on the server where students could access it about seventeen minutes after the issue was identified.

Our department currently operates independently as the capability is developed. The result is no production costs since the department already has all the equipment and software needed for the process. The system is based on Apple ${ }^{\mathrm{TM} M A C}$ OSX ${ }^{\mathrm{TM}}$ server software and Apple ${ }^{\mathrm{TM} M a c i n t o s h}$ computers. These are perceived to be the easiest applications with less technical expertise than required of Windows ${ }^{\mathrm{TM}}$ or UNIX ${ }^{\mathrm{TM}}$ systems.

\section{Conclusion}

Every college and university in the United States faces the same dilemma: increasing enrollment needs that outstrip budgets' abilities to add physical plant. On-line education is perceived to be a potential contributor to 
meeting the need for accelerating growth of enrollments while requiring less budget commitment than required by building new physical plant. The concern is developing a method of on-line course delivery that ensures the level of quality of course content to parallel the perceived quality of traditionally delivered courses. To be attractive to students as a learning option and then to be capable of maintaining the learner's interest to motivate completion of the course and, subsequently, degree programs, course materials must incorporate the tools to create edutainment. Simply, edutainment is course delivery in a style and format with diverse components that interest and educate in a way that keeps the learning returning for more. During the past few months, technology has introduced capabilities of producing edutainment, robust course content, at costs that make it very feasible as a course delivery option in any degree program.

\section{References}

1. Bartlett, Thomas (2003). "Big, but Not Bad: The Best Teaching Doesn't Always Happen Around a Seminar Table." The Chronicle of Higher Education. May 9, 2003.

2. Bork, Alfred et al (1992). "The Irvine-Geneva Course Development System", Education and Society, R. Aiken (Editor), Information Processing 92, Volume II, Elsevier Science Publishers.

3. Bork, Alfred (1995). "Distance Learning and Interaction: Toward a Virtual Learning Institute", Journal of Science Education and Technology, Volume 4.

4. Bork, Alfred (1996). "Rebuilding Universities with Highly Interactive Multimedia Curriculum," International Journal of Engineering Education, Volume 12.

5. Bork, Alfred (1999). "Global Distance Learning Institutes Based on Highly Interactive Learning Concept". Draft.

6. Bork, Alfred (1999). An Interview with Alfred Bork - The Future of Learning, EDUCOM Review, July/August.

7. Closing the Gap. (2001) Strategic Report, Texas Higher Education Coordinating Board. Austin, Texas.

8. Daniel, Sir John (1996). Mega-Universities and Knowledge Media, Kogan Page, London.

9. $\quad$ Daniel, Sir John (1997), "Why Universities Need Technological Strategies," Change, July/August.

10. Laurillard, Diana (1993). Rethinking University Teaching, Routledge, London.

11. Leonard, George (1987). Education and Ecstasy, North Atlantic Books.

12. Kuhn, Thomas (1998). The Structure of Scientific Revolutions, University of Chicago Press, third edition.

13. Norman, Donald (1998). The Invisible Computer, MIT Press.

14. Olsen, Florence (2003). "Business School Records Lectures and lets Students Review On-line." The Chronicle of Higher Education. Aug 8, 2003.

15. Sperry, R. W. (1972). Hemispheric specialization of mental faculties in the brain of man. In: M. P. Douglas (Ed.), The 36th Yearbook Claremont Reading Conference, pp. 126-136. Claremont: Claremont Graduate School.

16. Student Evaluations (2001-02). MANA 3335-91L Communication Policy and Strategy On-Line. David L. Sturges, Facilitator.

17. Sturges, D.L. and Minor, M. (2001). Distance Learning Can Be Hazardous to Your Health: Or, the Myth Adventures of On-line Learning. ITED Conference, Edinburg, Texas.

18. Tapscott, Don (1998).Growing Up Digital: The Rise of the Net Generation. McGraw-Hill Companies. New York, NY. 